\title{
Bacteriúria assintomática na gravidez de baixo risco - qual a evidência do seu tratamento?
}

\author{
Asymptomatic bacteriuria in low-risk pregnancy - what is the evidence of its treatment?
}

\section{Bacteriuria asintomática en el embarazo de bajo riesgo - ¿cuál es la evidencia de su tratamiento?}

\author{
Cátia Sofia Leocádio Cordeiro'1, Ana Isabel Ribeiro², Luís Filipe Cavadas \\ ${ }^{1}$ Unidade de Saúde Familiar Lagoa, Unidade Local de Saúde de Matosinhos, Porto, Portugal. \\ 2 Unidade de Saúde Familiar Nova Lousada, ACeS Tâmega III, Penafiel, Portugal.
}

\section{Resumo}

\begin{abstract}
A bacteriúria assintomática (BUA) tem estado associada a aumento do risco de pielonefrite materna e parto pré-termo. As normas de orientação clínica internacionais recomendam a sua pesquisa e tratamento durante a gravidez. No entanto, os benefícios e riscos da sua pesquisa e tratamento não são consensuais. Esta revisão tem por objetivo analisar a evidência disponível quanto à influência do tratamento da BUA na morbimortalidade materna e fetal. Os autores realizaram pesquisa na base de dados MEDLINE e sites de Medicina Baseada na Evidência, de revisões baseadas na evidência, normas de orientação clínica, meta-análises, revisões sistemáticas e ensaios clínicos controlados e aleatorizados, utilizando os termos MeSH: Bacteriuria e Pregnancy, de artigos publicados entre janeiro de 2008 e maio de 2018, em Inglês, Francês, Espanhol e Português. Para avaliação dos níveis de evidência e atribuição de forças de recomendação, foi utilizada a escala Strength of Recommendation Taxonomy (SORT) da American Family Physician. Foram identificados 136 artigos, dos quais 10 cumpriam critérios de inclusão. A evidência existente, maioria baseada em estudos antigos com importantes limitações metodológicas, não permite concluir de forma clara se o tratamento da BUA influencia positivamente a morbimortalidade materna e fetal, no entanto dados recentes apontam para ausência de benefício com o tratamento da BUA em gravidezes únicas de baixo risco (Força de recomendação B), o que questiona a prática clínica corrente. Para colmatar as limitações dos estudos encontrados, são necessários estudos controlados, aleatorizados, de elevada qualidade e maior dimensão que avaliem a influência do tratamento da BUA na morbimortalidade materna e fetal.
\end{abstract}

Palavras-chave: Bacteriúria; Gravidez; Nascimento Prematuro; Atenção Primária à Saúde

Como citar: Cordeiro CSL, Ribeiro Al, Cavadas LF. Bacteriúria assintomática na gravidez de baixo risco - qual a evidência do seu tratamento? Rev Bras Med Fam Comunidade. 2019;14(41):1922. https://doi.org/10.5712/rbmfc14(41)1922
Autor correspondente: Cátia Sofia Leocádio Cordeiro. E-mail: catiacordeironr15@gmail.com Fonte de financiamento: declaram não haver.

Parecer CEP: não se aplica.

Procedência e revisão por pares: revisado por pares. Recebido em: 18/11/2018. Aprovado em: 01/08/2019. 


\begin{abstract}
Asymptomatic bacteriuria (ASB) has been associated with an increased risk of maternal pyelonephritis (PN) and preterm birth (PTB). International clinical guidelines recommend its research and treatment during pregnancy. However, the benefit and risk of screening and treating ASB is not consensual, and this review intends to analyze the available evidence regarding the influence of ASB treatment on maternal and fetal morbidity and mortality. We search on MEDLINE database and Evidence-Based Medicine sites of evidence-based reviews, clinical guidelines, meta-analysis, systematic reviews and randomized controlled trials, using the MeSH terms "Bacteriuria AND Pregnancy", of articles published between January 2008 and May 2018, in English, French, Spanish and Portuguese. The Strength of Recommendation Taxonomy (SORT) scale of the American Family Physician was used to assess the levels of evidence and assignment of recommendation forces. We identified 136 articles, of which ten met the inclusion criteria. The existing evidence, mostly based on outdated or small and with methodological shortcomings clinical trials, does not allow a clear conclusion as to whether the treatment of ASB positively influences maternal and fetal morbidity and mortality; the most recent data effectively points to a lack of benefit with ASB treatment (SOR B). To address the limitations of the studies found, controlled, randomized, higher quality and larger studies are needed to assess the influence of ASB treatment on maternal and fetal morbidity and mortality.
\end{abstract}

Keywords: Bacteriuria; Pregnancy; Premature Birth; Primary Health Care

\title{
Resumen
}

La bacteriuria asintomática (BUA) se ha asociado a un aumento del riesgo de pielonefritis materna y parto prematuro. Las pautas en general recomiendan la detección y tratamiento de BUA en el embarazo. Sin embargo, el beneficio y riesgo de la detección y tratamiento de la BUA no son consensuales, y esta revisión pretende analizar la evidencia disponible sobre la influencia del tratamiento de la BUA en la morbilidad y mortalidad materna y fetal. Buscamos en la base de datos MEDLINE y en los sitios de Medicina Basada en la Evidencia, de revisiones basadas en la evidencia, guías clínicas, metanálisis, revisiones sistemáticas y ensayos controlados aleatorios, utilizando los términos MeSH "Bacteriuria Y Embarazo", de artículos publicados entre enero 2008 y mayo de 2018, en inglés, francés, español y portugués. Para la evaluación de los niveles de evidencia y asignación de fuerzas de recomendación, se utilizó la escala Strength of Recommendation Taxonomy (SORT) de la American Family Physician. Se identificaron 136 artículos, de los cuales 10 cumplían los criterios de inclusión. La evidencia existente, basada principalmente en ensayos clínicos obsoletos o pequeños y con deficiencias metodológicas, no permite una conclusión clara sobre si el tratamiento de la BUA influye positivamente la morbilidad y mortalidad materna y fetal; los datos más recientes apuntan a una falta de beneficio con el tratamiento de la BUA (SOR B). Para colmar las limitaciones de los estudios encontrados se necesitan estudios controlados, aleatorizados, de mayor calidad y tamaño para evaluar la influencia del tratamiento de la BUA en la morbilidad y mortalidad materna y fetal.

Palabras clave: Bacteriuria; Embarazo; Nacimiento Prematuro; Atención Primaria de Salud

\section{Introdução}

A bacteriúria assintomática (BUA) corresponde à presença de bacteriúria significativa sem os sintomas cardinais da infecção do trato urinário (ITU). Ocorre em $2 \%$ a $10 \%$ das grávidas. ${ }^{1}$ A maioria das normas americanas e europeias recomendam o rastreio e consequente tratamento da BUA durante a gravidez. ${ }^{2-7}$ No entanto, estas recomendações são baseadas em estudos realizados majoritariamente nos anos $60 \mathrm{e}$ 70 do século $X X$, de baixa qualidade, com importantes limitações metodológicas e opções terapêuticas obsoletas, não possibilitando a sua generalização para a realidade atual. Dada a limitação dos estudos em que se baseia, a eficácia do rastreio e tratamento generalizado da BUA na grávida de baixo risco torna-se, assim, questionável. Neste contexto, os autores realizaram uma revisão baseada na evidência, com o objetivo de determinar se o tratamento da BUA na gravidez de baixo risco influencia a morbidade e mortalidade materna e fetal.

\section{Métodos}

Foi realizada uma pesquisa nas bases de dados MEDLINE, Guidelines Finder, National Guideline Clearinghouse, Canadian Medical Association Infobase, The Cochrane Library, DARE, Bandolier e TRIP Database, de revisões baseadas na evidência, normas de orientação clínica, meta-análises, revisões 
sistemáticas e ensaios clínicos controlados e aleatorizados, utilizando os termos MeSH: Bacteriuria e Pregnancy, de artigos publicados desde 1 de janeiro de 2008 até 31 de maio de 2018, em inglês, francês, espanhol e português. No Índex de Revistas Médicas Portuguesas, a pesquisa foi realizada através da combinação dos termos da lista dos Descritores em Ciências da Saúde (DeCS), utilizando os descritores em português: Bacteriúria e Gravidez.

Os critérios de inclusão utilizados nesta revisão foram os seguintes:

- População - grávidas assintomáticas com gravidez de baixo risco

- Intervenção - tratamento antibiótico da bacteriúria assintomática

- Comparação - tratar bacteriúria assintomática versus não tratar bacteriúria assintomática versus placebo

- Resultados - morbimortalidade materna e fetal

A fim de avaliar a qualidade dos estudos e a força de recomendação, os autores optaram por utilizar a escala de Strength of Recommendation Taxonomy (SORT) da American Family Physician. De acordo com esta taxonomia, a qualidade do estudo é subdividida em três Níveis de Evidência (Nível de Evidência 1: estudos de boa qualidade, evidência orientada para o doente; Nível de Evidência 2: estudos de qualidade limitada, evidência orientada para o doente; e Nível de Evidência 3: outra evidência) e a Força de Recomendação em três graus (Força de Recomendação A: consistente, evidência orientada para o doente; Força de Recomendação B: inconsistente ou qualidade limitada, evidência orientada para o doente; e Força de Recomendação C: consensos, evidência orientada para a doença).

\section{Resultados}

Da pesquisa bibliográfica efetuada foram identificados 136 artigos. Os artigos repetidos foram excluídos. Foram assim selecionados 10 artigos que cumpriam os critérios de inclusão: seis normas de orientação clínica, uma meta-análise, duas revisões sistemáticas e um ensaio clínico.

Os pontos essenciais das normas de orientação clínica incluídas nesta revisão encontram-se descritos no Quadro 1.

Quadro 1. Normas de orientação clínica.

\begin{tabular}{|c|c|c|}
\hline Autor, ano (referência) & Recomendações & Força de Recomendação \\
\hline $\begin{array}{l}\text { EAU } \\
2018^{2}\end{array}$ & $\begin{array}{l}\text { Baseado nos efeitos benéficos maternos e fetais do tratamento antibiótico, as } \\
\text { grávidas devem ser rastreadas e tratadas para bacteriúria assintomática. }\end{array}$ & B \\
\hline $\begin{array}{l}\text { SOGC } \\
2012^{4}\end{array}$ & $\begin{array}{l}\text { Tratamento na grávida de BUA } \geq 100.000 \mathrm{CFU} / \mathrm{mL} \text { com antibioterapia apropriada } \\
\text { (SOGC II - 2A) }\end{array}$ & $\mathrm{B}$ \\
\hline $\begin{array}{l}\text { USPSTF } \\
2008^{6}\end{array}$ & $\begin{array}{l}\text { Rastrear BUA por urocultura nas grávidas entre a } 12^{a} \text { e a } 16^{a} \text { semana de } \\
\text { gestação ou na } 1^{\text {a }} \text { consulta pré-natal e tratar adequadamente (USPSTF - A) }\end{array}$ & $\mathrm{B}$ \\
\hline $\begin{array}{l}\text { NICE } \\
2008^{7}\end{array}$ & $\begin{array}{l}\text { Rastrear BUA por urocultura no início da gravidez e tratar adequadamente para } \\
\text { redução do risco de pielonefrite }\end{array}$ & B \\
\hline
\end{tabular}


De acordo com a United States Preventive Services Task Force de 2008, o rastreio e tratamento da BUA nas grávidas reduz significativamente a incidência de infeção do trato urinário sintomática e baixo peso de nascimento, recomendando assim o seu rastreio através de urocultura, nas grávidas entre a $12^{\mathrm{a}}$ e a $16^{\mathrm{a}}$ semana de gestação, tendo sido atribuída por esta entidade uma força de recomendação $A{ }^{6}$ Segundo o National Institute for Health and Care Excellence, em 2008, a identificação e tratamento da BUA na grávida reduz o risco de pielonefrite, recomendando o seu rastreio através de urocultura no início da gravidez, mas sem atribuição de uma força de recomendação. ${ }^{7}$

A Society of Obstetricians and Gynaecologists of Canada em 2012 recomenda o tratamento na grávida da BUA, baseando-se na premissa de que o tratamento da bacteriúria assintomática reduz o risco de pielonefrite e baixo peso de nascimento, apesar de não reduzir significativamente o risco de parto pré-termo, atribuindo assim uma força de recomendação II - $2 A .{ }^{4}$ Já a Scottish Intercollegiate Guidelines Network de 2012 recomenda o tratamento da BUA nas grávidas, referindo que o seu tratamento reduz o risco de pielonefrite, parto pré-termo e baixo peso de nascimento, atribuindo uma força de recomendação $A .{ }^{5}$

A American Academy of Pediatrics em conjunto com o American College of Obstreticians and Gynecologists, em 2012, recomendam o tratamento da BUA e consequente confirmação de cura, caso seja realizada uma urocultura no início da gravidez. ${ }^{3}$

A European Urology Academy de 2018 refere que, segundo a evidência disponível, o tratamento da BUA em mulheres grávidas parece ser benéfico. No entanto, afirma que a evidência é baixa e não é apoiada por um estudo recente de 2015, com boa qualidade metodológica. Recomenda, assim, o rastreio e tratamento de curta duração, atribuindo uma força de recomendação fraca. ${ }^{2}$

Das normas encontradas, verificamos basearem-se em artigos com limitações metodológicas importantes, a maioria datados de 1960 a 1987, e que geraram atribuição de diferentes forças de recomendação entre as entidades. Assim, e de acordo com a escala SORT, atribuímos a estas normas de orientação clínica uma força de recomendação $B$, excetuando a norma da AAP/ACOG, a que atribuímos uma força de recomendação $C$ por ser uma norma baseada em consenso de peritos.

Os dados principais das revisões sistemáticas, da meta-análise e do ensaio clínico encontram-se descritos nos Quadros 2, 3 e 4, respectivamente.

Smaill \& Vazquez $^{8}$ realizaram uma revisão sistemática com o objetivo de determinar o efeito do tratamento da bacteriúria assintomática no desenvolvimento de pielonefrite e no risco de baixo peso de nascimento e parto pré-termo, tendo sido publicada em 2015 na Cochrane Library. Como critérios de seleção, incluíram ensaios clínicos randomizados que comparavam o tratamento com placebo ou a ausência de tratamento em grávidas com bacteriúria assintomática descoberta em exame de rotina pré-natal. Dois revisores avaliaram independentemente os ensaios clínicos para inclusão e o risco de viés. Foram então incluídos 14 estudos, envolvendo quase 2000 grávidas.

De acordo com os autores, o tratamento antibiótico em comparação com placebo ou nenhum tratamento reduziu a incidência de pielonefrite (razão de risco médio (RR) 0,23 , intervalo de confiança (IC) de 95\% 0,13-0,41; em 11 estudos, com 1932 mulheres; evidência de qualidade muito baixa). O tratamento com antibióticos foi também associado à redução na incidência de baixo peso de nascimento (RR médio 
Quadro 2. Revisões sistemáticas

\begin{tabular}{|c|c|c|c|c|c|}
\hline $\begin{array}{l}\text { Autor, ano } \\
\text { (Referência) }\end{array}$ & População & $\begin{array}{l}\text { Intervenção e } \\
\text { comparação }\end{array}$ & Resultados principais & Conclusões & $\begin{array}{l}\text { Nível de } \\
\text { Evidência }\end{array}$ \\
\hline $\begin{array}{l}\text { Smaill \& } \\
\text { Vazquez, } \\
2015^{8}\end{array}$ & $\begin{array}{c}14 \text { ECA } \\
\mathrm{N}=2000 \\
\text { Grávidas com BUA } \\
\text { (ensaios publicados } \\
\text { entre } 1960 \text { e 1987) }\end{array}$ & $\begin{array}{l}\text { Tratamento da BUA, } \\
\text { não tratamento ou } \\
\text { placebo (diferentes } \\
\text { regimes antibióticos } \\
\text { e duração do } \\
\text { tratamento) }\end{array}$ & $\begin{array}{l}\text { Grupos intervenção: } \\
\text { Redução incidência PN (RR 0,23, } \\
\text { IC 95\% 0,13-0,41), parto pré-termo } \\
\text { (RR 0,27, IC 95\% 0,11-0,62) e baixo } \\
\text { peso de nascimento (RR 0,64, IC } \\
95 \% 0,45-0,93 \text { ) } \\
\text { Maioria dos ensaios classificados } \\
\text { como de baixa qualidade }\end{array}$ & $\begin{array}{l}\text { Tratamento BUA } \\
\text { na gravidez reduz } \\
\text { a incidência de PN } \\
\text { e baixo peso de } \\
\text { nascimento }\end{array}$ & 2 \\
\hline $\begin{array}{l}\text { Angelescu } \\
\text { et al., } 2016^{9}\end{array}$ & $\begin{array}{c}4 \text { ECA } \\
\mathrm{N}=454 \\
\text { Grávidas com BUA }\end{array}$ & $\begin{array}{l}\text { Tratamento da BUA, } \\
\text { não tratamento ou } \\
\text { placebo }\end{array}$ & $\begin{array}{l}\text { Williams et al. (1969); } \\
\text { Mulla (1960) } \\
\text { - Antibioterapia reduz } \\
\text { significativamente o risco de } \\
\text { pielonefrite (OR=0,21, IC } 95 \% \\
0,007-0,59 \text {; evidência de baixa } \\
\text { qualidade) } \\
\text { Kazemier et al. (2015) } \\
\text { - Taxas de eventos não são } \\
\text { estatisticamente significativas para } \\
\text { pielonefrite }(0 \% \text { vs. } 2,2 \% \text {; OR=0,37, } \\
\text { IC 95\% 0,01-9,25, } p=0,515)\end{array}$ & $\begin{array}{l}\text { Até a data, não existe } \\
\text { evidência confiável } \\
\text { que apoie o rastreio } \\
\text { da BUA por rotina } \\
\text { nas grávidas }\end{array}$ & 2 \\
\hline
\end{tabular}

Quadro 3. Meta-análise.

\begin{tabular}{|c|c|c|c|c|c|}
\hline $\begin{array}{l}\text { Autor, ano } \\
\text { (Referência) }\end{array}$ & População & $\begin{array}{l}\text { Intervenção e } \\
\text { comparação }\end{array}$ & Resultados principais & Conclusões & $\begin{array}{c}\text { Nível de } \\
\text { Evidência }\end{array}$ \\
\hline $\begin{array}{l}\text { Köves et al., } \\
2017^{10}\end{array}$ & $\begin{array}{l}13 \text { ECA } \\
\text { N=2281 } \\
\text { Grávidas } \\
\text { com BUA }\end{array}$ & $\begin{array}{l}\text { Tratamento } \\
\text { da BUA, não } \\
\text { tratamento ou } \\
\text { placebo }\end{array}$ & $\begin{array}{l}\text { Meta-análise de } 11 \text { ECAs ( } \mathrm{n}=2002) \text { : } \\
\text { Antibioterapia reduz significativamente as } \\
\text { ITUs vs placebo/não tratamento }(\mathrm{RR}=0,22 \text {, } \\
\text { IC } 95 \% 0,12-0,40 \text {; evidência de muito baixa } \\
\text { qualidade) } \\
8 \text { ECAs ( } \mathrm{n}=1689 \text { ): } \\
\text { Antibioterapia reduz risco de baixo peso de } \\
\text { nascimento ( } \mathrm{RR}=0,58, \mathrm{IC} 95 \% 0,36-0,94 ; \\
\text { evidência de muito baixa qualidade) } \\
4 \text { ECAs ( } \mathrm{n}=854) \text { : } \\
\text { Antibioterapia reduz risco de parto pré- } \\
\text { termo ( } \mathrm{RR}=0,34, \text { IC } 95 \% 0,18-0,66 \text {; } \\
\text { evidência de baixa qualidade) } \\
1 \text { ECA ( } \mathrm{n}=85) \text { : } \\
\text { Não encontrou benefício na antibioterapia; } \\
\text { maior qualidade metodológica }\end{array}$ & $\begin{array}{l}\text { Tratamento da BUA na } \\
\text { gravidez reduz o risco de ITU } \\
\text { sintomática, baixo peso de } \\
\text { nascimento e parto pré-termo } \\
\text { (evidência de qualidade baixa } \\
\text { a muito baixa) Um ensaio } \\
\text { clinico recente de maior } \\
\text { qualidade metodológica } \\
\text { não encontrou benefícios na } \\
\text { antibioterapia }\end{array}$ & 2 \\
\hline
\end{tabular}

0,64, IC 95\% 0,45-0,93; em 6 estudos, com 1437 bebês; evidência de baixa qualidade) e prematuridade (RR 0,27, IC 95\% 0,11-0,62; em 2 estudos, com 242 mulheres; evidência de baixa qualidade). Segundo os autores, foi ainda observada uma redução na bacteriúria persistente no momento do parto (média RR 0,30, IC 95\% 0,18-0,53; em 4 estudos, com 596 mulheres; evidência de baixa qualidade). No entanto, os dados foram muito limitados relativamente ao efeito dos antibióticos em outros resultados neonatais e os efeitos adversos maternos foram raramente descritos. No geral, todos os 14 estudos tinham um risco de viés alto ou pouco claro, e muitos careciam de uma descrição adequada dos métodos. A evidência de pielonefrite, parto prematuro e baixo peso de nascimento foi avaliada como de baixa ou muito baixa qualidade. 
Quadro 4. Ensaio clínico.

\begin{tabular}{|c|c|c|c|c|c|}
\hline $\begin{array}{l}\text { Autor, ano } \\
\text { (Referência) }\end{array}$ & População & $\begin{array}{l}\text { Intervenção e } \\
\text { comparação }\end{array}$ & Resultados principais & Conclusões & $\begin{array}{l}\text { Nível de } \\
\text { Evidência }\end{array}$ \\
\hline $\begin{array}{l}\text { Kazemier } \\
\text { et al., } 2015 \\
\text { Holanda }^{11}\end{array}$ & $\begin{array}{c}\mathrm{N}=4283 \\
\text { Grávidas, gravidez } \\
\text { única de baixo risco, } \\
\text { 16-22 semanas (248 } \\
\text { com BUA) } \\
\text { Estudo coorte } \\
\text { prospectivo } \\
\text { multicêntrico com } \\
\text { ECA duplo cego } \\
\text { controlado por } \\
\text { placebo }(\mathrm{n}=85)\end{array}$ & $\begin{array}{l}\text { Tratamento com } \\
\text { nitrofurantoína } \\
\text { (100mg 2id, } 5 \text { dias) } \\
\text { vs. não tratamento/ } \\
\text { placebo }\end{array}$ & $\begin{array}{l}\text { Taxas de eventos não estatisticamente } \\
\text { diferentemente significativas para PN } \\
(0 \% \text { vs. } 22,2 \% \text {; OR=0,37, IC 95\% 0,01- } \\
9,25, p=0,515) \\
\text { Pielonefrite, parto pré-termo ou ambos: } \\
\text { - ausência de diferenças } \\
\text { estatisticamente significativas: não } \\
\text { tratadas/placebo BUA+ vs. BUA- ([OR] } \\
\text { 1,5, IC } 95 \% 0,6-3,5) \\
\text { - ausência de diferenças } \\
\text { estatisticamente significativas: BUA+ } \\
\text { tratada vs. não tratada/placebo BUA+ } \\
\text { (diferença risco - 0,4, IC 95\% 3,6-9,4) } \\
\text { Ausência de diferenças estatisticamente } \\
\text { significativas nas taxas de parto pré- } \\
\text { termo, morbilidade infantil e mortalidade } \\
\text { perinatal }\end{array}$ & $\begin{array}{l}\text { Na gravidez de } \\
\text { baixo risco, a BUA } \\
\text { não está associada } \\
\text { a parto pré-termo } \\
\text { O risco absoluto } \\
\text { de PN na BUA não } \\
\text { tratada é baixo }\end{array}$ & 2 \\
\hline
\end{tabular}

Os autores concluíram assim que, embora o tratamento com antibióticos seja eficaz na redução do risco de pielonefrite na gravidez, a estimativa do efeito é muito incerta, devido à qualidade muito baixa das evidências. Concluem ainda que a redução do baixo peso ao nascer e parto prematuro com tratamento antibiótico é consistente com as teorias sobre o papel da infeção nos desfechos adversos da gravidez, mas afirmam que essa associação deve ser interpretada com cautela, dada a qualidade muito pobre dos estudos incluídos. Deste modo, tendo em conta que as conclusões desta revisão sistemática foram baseadas em estudos com importantes limitações metodológicas, sendo apesar de tudo orientados para o doente, atribuímos a este artigo um nível de evidência 2.

Angelescu et al. ${ }^{9}$, em 2016, realizaram uma revisão sistemática tendo por objetivos avaliar os benefícios relevantes para o doente e os malefícios do rastreio da bacteriúria assintomática versus nenhum rastreio, comparar os benefícios e malefícios de diferentes estratégias de rastreio, e determinar os benefícios e malefícios do tratamento da bacteriúria assintomática. Dois revisores avaliaram independentemente os artigos para inclusão e o risco de viés. Segundo os autores, não encontraram nenhum estudo elegível que investigasse os benefícios e malefícios do rastreio da bacteriúria assintomática versus nenhum rastreio ou que comparasse diferentes estratégias de rastreio. Encontraram apenas quatro ensaios clínicos randomizados, que foram incluídos na revisão, comparando o tratamento com antibióticos com a ausência de tratamento ou placebo, em 454 mulheres grávidas com bacteriúria assintomática.

De acordo com os autores, os resultados de dois estudos publicados na década de 1960 mostraram uma redução estatisticamente significativa nas taxas de pielonefrite (odds ratio [OR] $=0,21,95 \%$ IC 0,07-0,59) e menor incidência de ITU (OR=0,10, IC 95\% 0,03-0,35) em mulheres tratadas com antibióticos; no entanto, as taxas de eventos relatadas por um estudo recente não foram estatisticamente diferentes em relação à pielonefrite $(0 \%$ vs. $2,2 \%$; $O R=0.37, I C ~ 0,01-9.25, p=0,515)$ e à cistite durante a gravidez $(10 \%$ vs. $18 \%$; odds ratio Peto $[\mathrm{POR}]=0,53, \mathrm{IC} 0,16-1,79, \mathrm{p}=0,357)$. Os autores afirmam que, como três dos quatro estudos incluídos foram conduzidos há várias décadas e apresentam importantes limitações metodológicas, a aplicabilidade dos seus resultados à realidade atual dos cuidados de saúde é provavelmente baixa. $\mathrm{O}$ 
ensaio clínico recente de alta qualidade foi interrompido precocemente devido a um número muito baixo de eventos de desfecho primário; os resultados não mostraram um benefício do tratamento da bacteriúria assintomática. Os autores concluíram assim que, até ao momento, não existe evidência confiável que apoie o rastreio da BUA por rotina nas mulheres grávidas. Com base na descrição feita por Angelescu et al. das limitações dos estudos incluídos, atribuímos a esta revisão sistemática um nível de evidência 2.

Köves et al. ${ }^{10}$, em 2017 , desenvolveram uma revisão sistemática e meta-análise baseados na premissa de que, muitas vezes, pessoas com bacteriúria assintomática são desnecessariamente tratadas com antibióticos, com riscos de efeitos adversos e resistência antimicrobiana. Os autores realizaram assim uma revisão sistemática com o objetivo de determinar os benefícios e malefícios do tratamento da BUA em grupos específicos de doentes. A extração de dados, o risco de viés e a avaliação da qualidade foram realizados por dois revisores de forma independente. Foram incluídos 13 ensaios clínicos, envolvendo 2281 mulheres grávidas com BUA. Segundo os autores, de modo geral, a qualidade da evidência variou de muito baixa a baixa.

De acordo com a meta-análise envolvendo 11 ensaios clínicos ( $n=2002)$, o tratamento reduz significativamente o número de infeções do trato urinário sintomáticas em grávidas com $B U A(R R=0,22, I C$ 95\% 0,12-0,40; evidência de muito baixa qualidade); seis ensaios clínicos ( $n=716)$ mostraram o benefício do tratamento na resolução da BUA ( $R R=2,99$, IC 95\% 1,65-5,39; evidência de muito baixa qualidade); oito ensaios clínicos ( $n=1689)$ mostraram que o tratamento reduz o risco de baixo-peso de nascimento $(R R=0,58$, IC 95\% 0,36-0,94; evidência de muito baixa qualidade); quatro ensaios clínicos ( $n=854$ ) mostraram que o tratamento reduz o risco de parto pré-termo ( $R R=0,34$, IC 95\% 0,18-0,66; evidência de baixa qualidade); um ensaio clínico $(n=248)$ de maior qualidade metodológica não mostrou benefícios com o tratamento da bacteriúria assintomática (diferença risco = 0,4, IC 95\% 3,6-9,4).

Os autores concluem que existe evidência de que o tratamento da bacteriúria assintomática em mulheres grávidas diminui o risco de ITU sintomática, baixo peso ao nascer e prematuridade, e sugerem o seu tratamento. Tendo em conta as evidentes limitações metodológicas dos estudos incluídos nesta meta-análise e revisão sistemática, atribuímos-Ihe um nível de evidência 2.

Kazemier et al. ${ }^{11}$, em 2015, publicaram um estudo de coorte prospetivo multicêntrico com um ensaio clínico aleatorizado e controlado, envolvendo mulheres grávidas com idade superior a 18 anos, com gravidez única, frequentadoras de oito hospitais e cinco centros de ecografia da Holanda. Estas mulheres efetuaram rastreio de BUA entre a $16^{a}$ e a $22^{a}$ semana de gestação, e foram acompanhadas até a $6^{a}$ semana pósparto. Aquelas que positivaram para BUA foram elegíveis para participar no estudo controlado randomizado, comparando o tratamento com nitrofurantoína com o tratamento com placebo. Após exclusão dos testes contaminados e das participantes perdidas na fase de acompanhamento, obtiveram um total de 4283 grávidas, das quais 248 tinham BUA. Dessas, 40 foram aleatoriamente designadas para tratamento com nitrofurantoína e 45 para tratamento com placebo, enquanto que as outras 163 grávidas com BUA foram acompanhadas sem tratamento.

De acordo com os autores, a proporção de grávidas com pielonefrite, parto prematuro, ou ambos não diferiu entre as grávidas com BUA não tratadas ou tratadas com placebo e as grávidas sem BUA (6 [2,9\%] de 208 versus 77 [1,9\%] de 4035, razão de chances ajustada [OR] = 1,5; IC 95\% 0,6-3,5) ou entre as grávidas com BUA tratadas com nitrofurantoína versus aquelas que não foram tratadas ou receberam 
placebo (1 [2,5\%] de 40 vs. 6 [2,9\%] de 208, diferença de risco = 0,4, IC 95\% 3,6-9,4). As grávidas com BUA não tratadas e tratadas com placebo desenvolveram pielonefrite em cinco $(2,4 \%)$ de 208 casos, em comparação com 24 (0,6\%) de 4035 grávidas sem BUA (OR ajustado 9,9\%, IC 95\% 1,4-11,4).

Os autores concluem assim que, em mulheres com gestação única e sem complicações, a BUA não está associada a parto pré-termo, e que, apesar de associada ao desenvolvimento de pielonefrite, o risco absoluto de pielonefrite na BUA não tratada é baixo, alertando assim para a prática questionável do seu tratamento por rotina durante a gravidez. Com base nos resultados deste estudo, apesar da sua boa qualidade metodológica e orientação para o doente, as autoras julgam necessário maior dimensão da amostra do ensaio clínico e período de acompanhamento mais alargado, pelo que atribuem um nível de evidência 2.

\section{Discussão}

A maioria da bibliografia encontrada é baseada em estudos realizados entre 1960 e 1987, estudos esses que apresentavam apenas uma descrição breve e incompleta dos métodos de pesquisa bem como uma descrição incompleta dos resultados. A descrição das características dos participantes no estudo também era pobre, não descrevendo nomeadamente a eventual existência de infecções genitais concomitantes. Para além disso, não se verificou a utilização de uma definição padrão consistente para os resultados médicos avaliados, e não apresentaram dados suficientes que permitissem comparar as idades gestacionais entre os grupos de tratamento e os grupos controlo.

Outra limitação encontrada prende-se na utilização de antibióticos já não usados na atualidade, ou contraindicados na gravidez, como as tetraciclinas, bem como a ausência de descrição de potenciais efeitos adversos dos fármacos instituídos. No geral, os estudos não foram metodologicamente fortes e, na sua maioria, não descreveram adequadamente a ocultação da alocação, nem houve descrição do método de randomização ou o método era claramente inadequado.

Outro fator importante e que merece discussão prende-se na idade gestacional ótima para realizar o rastreio da bacteriúria assintomática. Um estudo mais antigo defende que o rastreio deve ser realizado a partir da $20^{\mathrm{a}}$ semana de gestação, sob pena de podermos perder mais de metade das grávidas com bacteriúria assintomática. No estudo mais recente, de 2015, foram selecionadas grávidas entre a $16^{a}$ e a $22^{a}$ semana de gestação, e não se encontrou benefício no tratamento da bacteriúria assintomática. $A$ maioria das guidelines recomenda o rastreio e tratamento da BUA no $1^{\circ}$ trimestre da gravidez, pelo que se coloca a questão sobre se haverá ou não uma idade gestacional ótima, em que o tratamento da bacteriúria assintomática poderá ser benéfico.

\section{Conclusão}

A evidência existente não permite concluir de forma clara se o tratamento de BUA influencia positivamente a morbimortalidade materna e fetal. Os dados mais recentes apontam efetivamente para uma ausência de benefício com o tratamento da BUA (Força de recomendação B) em gravidezes únicas, de baixo risco, o que pode pôr em causa a prática clínica corrente. Para suprir as limitações dos estudos encontrados, são necessários estudos controlados, aleatorizados, de elevada qualidade e maior dimensão que avaliem a influência do tratamento da BUA na morbimortalidade materna e fetal. 


\section{Contribuição dos autores}

Concepção e/ou delineamento do estudo: CSLC, AIR, LFC. Aquisição, análise ou interpretação dos dados: CSLC, AIR, LFC. Redação preliminar: CSLC. Revisão crítica da versão preliminar: CSLC, AIR, LFC. Todos os autores aprovaram a versão final e concordaram com prestar contas sobre todos os aspectos do trabalho.

\section{Conflito de interesses}

Declaram não haver.

\section{Referências}

1. Direcção Geral de Saúde. Norma no 037/2011, de 30/09/2011. atualizada em 20/12/2013. [acesso 2018 Jun 20]. Disponível em: https:// www.dgs.pt/directrizes-da-dgs/normas-e-circulares-normativas/norma-n-0372011-de-30092011.aspx

2. Bonkat G, Bartoletti RR, Bruyère F, Cai T, Geerlings SE, Köves B, et al.; European Association of Urology. Urological infections. Arnhem: European Association of Urology; 2018. [acesso 2018 Jun 20]. Disponível em: http://uroweb.org/guideline/urological-infections/

3. American Academy of Pediatrics Committee on Fetus and Newborn/American College of Obstetricians and Gynaecologists Committee on Obstetric Practice, Guidelines for Perinatal Care 7th ed. Elk Grove Village/Washington: American Academy of Pediatrics/American College of Obstetricians and Gynaecologists; 2013.

4. Allen VM, Yudin MH; Infectious Diseases Committee. Management of group B streptococcal bacteriuria in pregnancy. J Obstet Gynaecol Can. 2012;34(5):482-86. https://doi.org/10.1016/S1701-2163(16)35246-X

5. Scottish Intercollegiate Guidelines Network. Management of suspected bacterial urinary tract infection in adults. Edinburgh: Scottish Intercollegiate Guidelines Network; 2012.

6. U.S. Preventive Services Task Force. Screening for asymptomatic bacteriuria in adults: U.S. Preventive Services Task Force reaffirmation recommendation statement. Ann Intern Med. 2008;149(1):43-7. https://doi.org/10.7326/0003-4819-149-1-200807010-00009

7. National Institute for Health and Clinical Excellence: Guidance. Antenatal Care: Routine Care for the Healthy Pregnant Woman. London: RCOG Press; 2008.

8. Smaill FM, Vazquez JC. Antibiotics for asymptomatic bacteriuria in pregnancy. Cochrane Database Syst Rev. 2015;(8):CD000490. https://doi.org/10.1002/14651858.CD000490.pub3

9. Angelescu K, Nussbaumer-Streit B, Sieben W, Scheibler F, Gartlehner G. Benefits and harms of screening for and treatment of asymptomatic bacteriuria in pregnancy: a systematic review. BMC Pregnancy Childbirth. 2016;16(1):336. https://doi.org/10.1186/s12884-016-1128-0

10. Köves B, Cai T, Veeratterapillay R, Pickard R, Seisen T, Lam TB, et al. Benefits and Harms of Treatment of Asymptomatic Bacteriuria: A Systematic Review and Meta-analysis by the European Association of Urology Urological Infection Guidelines Panel. Eur Urol. 2017;72(6):865-8. https://doi.org/10.1016/j.eururo.2017.07.014

11. Kazemier BM, Koningstein FN, Schneeberger C, Ott A, Bossuyt PM, de Miranda E, et al. Maternal and neonatal consequences of treated and untreated asymptomatic bacteriuria in pregnancy: a prospective cohort study with an embedded randomised controlled trial. Lancet Infect Dis. 2015;15(11):1324-33. https://doi.org/10.1016/S1473-3099(15)00070-5 